\title{
Análise da qualidade de vida em pacientes com Acidente Vascular Cerebral
}

\author{
Alba Barros Souza Fernandes
}

\section{SÍNTESE}

$\mathrm{O}$ artigo "Qualidade de vida em pacientes com Acidente Vascular Cerebral: Centro Clínica PUC-Minas Betim" de Scalzo et $\mathrm{al}^{1}$, tem o objetivo de determinar o perfil e avaliar a qualidade de vida dos pacientes com diagnóstico clínico de Acidente Vascular Cerebral (AVC) em tratamento na Clínica de Fisioterapia da Pontifícia Universidade Católica de Minas Gerais, Betim. Para tal, foram aplicados: um questionário para obter os dados sócio-demográficos, clínicos e físicos dos pacientes; o Mini-Exame do Estado Mental para avaliar a função cognitiva e selecionar os pacientes que estariam aptos a responderem o questionário de qualidade de vida; e o SF-36 (The Medical Outcomes Study 36-item Short-Form Health Survey) para avaliar o comprometimento da qualidade de vida em relação ao estado geral de saúde. Foram avaliados 47 pacientes (27 homens e 20 mulheres), com idade média de $60,4( \pm 10,1)$ anos. Destes, apenas 21 pacientes responderam ao SF-36. Foram observados baixos escores em todos os domínios do SF-36, principalmente nos aspectos físicos e capacidade funcional. Os escores no domínio capacidade funcional foram menores nos pacientes que necessitavam de auxílio para deambulação ou estavam restritos à cadeira de rodas. $\mathrm{O}$ tempo de AVC e o tempo de tratamento influenciaram positivamente os domínios estado geral de saúde e saúde mental. Os resultados encontrados mostram a piora da qualidade de vida em sobreviventes de AVC, principalmente pelo comprometimento dos aspectos físicos e capacidade funcional.

\section{RESUMO}

$\mathrm{O}$ resumo do artigo sintetiza bem a metodologia utilizada e alguns dos resultados encontrados no trabalho, mas importantes correlaçóes observadas entre os resultados não foram destacadas.

\section{INTRODUÇÃO}

A introdução do artigo traz um breve resumo do acidente vascular cerebral (AVC), incluindo definição, principais tipos, prevalência e manifestaçóes clínicas que irâo comprometer as atividades de vida diária, influenciando negativamente a qualidade de vida. A seguir, aborda a qualidade de vida, que pode ser avaliada tanto por escalas genéricas do estado de saúde, quanto por escalas específicas a uma determinada doença. Os autores dáo ênfase ao SF-36, um questionário genérico de qualidade de vida, que engloba oito domínios que avaliam desde o estado de saúde até o impacto da doença na vida diária do indivíduo.

Apesar dos conceitos referentes ao tema em questáo estarem muito bem descritos, os autores não apresentam a pergunta principal do estudo, assim como os objetivos do trabalho.

O estudo em questão é relevante, visto o crescente número de pessoas com doenças e incapacidades crônicas, o que tem gerado repercussóes sociais importantes. Dentre essas condiçóes, o AVC é a doença mais incapacitante, gerando prejuízo significativo na qualidade de vida dos indivíduos. A avaliação ou mensuração da qualidade de vida vem assumindo importância, sob vários aspectos, nos últimos anos, tanto de forma individual quanto coletiva. $\mathrm{O}$ avanço terapêutico e tecnológico fez com que a sobrevida de doentes, particularmente com doenças crônicas, aumentasse significativamente. Entretanto, frequentemente permanecem complicaçôes ou sequelas que causam limitaçôes com prejuízos da participaçáo em várias atividades ${ }^{2}$.

Os instrumentos genéricos de análise da qualidade de vida, como o SF-36, são menos sensíveis para explorar os efeitos de incapacidades gerados por uma doença específica em um indivíduo, podendo subestimar o impacto do $\mathrm{AVC}^{3}$, ao passo que a utilização de questionários específicos relaciona de forma mais

* Fisioterapeuta, Doutora em Ciências, Professora Adjunta do Centro Universitário Serra dos Órgáos (UNIFESO), Teresópolis-RJ, Brasil.

Endereço para correspondência: Estrada Wenceslau José de Medeiros, 1045, Prata CEP 25976-340, Teresópolis-RJ, Brasil. Tel: (21) 2743-5311 / Fax: (21) 2743-5303 
direta as alteraçóes na qualidade de vida à patologia propriamente dita.

O Stroke Specific Quality of Life Scale (SSQOL), traduzido para a língua portuguesa do Brasil e adaptado para a cultura brasileira, foi originalmente desenvolvido para medir a qualidade de vida de indivíduos com sequela de AVC. Contém 49 itens, distribuídos em 12 domínios (energia, papel familiar, linguagem, mobilidade, humor, personalidade, auto-cuidado, papel social, raciocínio, função de membro superior, visão e trabalho/produtividade) $)^{3}$.

\section{MÉTODO}

O presente artigo determina o perfil e avalia a qualidade de vida de pacientes com diagnóstico clínico de AVC que se encontram em tratamento na Clínica de Fisioterapia da Pontifícia Universidade Católica de Minas Gerais - Betim, através de um questionário sócio-demográfico, do Mini-Exame do Estado Mental, a fim de avaliar a função cognitiva desses pacientes, e do SF-36 (Medical Outcomes Short-Form Health Survey), que avalia a qualidade de vida.

Os critérios de exclusão de participação no estudo não foram citados no artigo, de forma que, durante a análise, não é possível responder se as alteraçóes encontradas na qualidade de vida foram decorrentes apenas do AVC ou se foram provenientes de alguma outra comorbidade que porventura também estivesse presente.

Os critérios de inclusão deveriam ser mais rígidos, visto que não está determinado o período pós AVC em que os pacientes se encontravam, assim como o tempo de tratamento dos pacientes avaliados. Esses fatos certamente influenciam a qualidade de vida.

Os autores informaram que a pesquisa foi aprovada pelo Comitê de Ética em Pesquisa da Pontifícia Universidade Católica de Minas Gerais (PUC Minas) e que os pacientes avaliados assinaram o Termo de Consentimento Livre e Esclarecido.

\section{RESULTADOS E DISCUSSÃO}

Os resultados apresentados neste estudo estão descritos no texto de forma clara, com a ilustração de uma figura.

Os autores observaram alteraçóes em todos os domínios do SF-36, principalmente nos aspectos físi- cos e capacidade funcional, o que era de se esperar. A maioria dos estudos envolvendo hemiplégicos no Brasil tem utilizado instrumentos genéricos de qualidade de vida, como o SF-36 e o Perfil de Saúde de Nottingham. Apesar de avaliarem a qualidade de vida de uma maneira geral, esses instrumentos são menos sensíveis para explorar os efeitos de incapacidades geradas por uma doença específica na qualidade de vida das pesso$a s^{3,4}$. Seria interessante que os autores também utilizassem um questionário de qualidade de vida específico para AVC, de forma a complementar o estudo, como o Stroke Specific Quality of Life Scale, que já foi traduzido para a língua portuguesa do Brasil e adaptado para a cultura brasileira ${ }^{3}$.

$\mathrm{Na}$ discussão, os autores abordam e discutem os resultados encontrados no presente estudo, comparando com dados da literatura. Todos os resultados encontrados são embasados, mesmo os que não são semelhantes aos de outros estudos.

Os autores estão conscientes das limitaçôes do estudo, deixando claro que concordam que a amostra, composta apenas por pessoas que estavam em atendimento, dificulta a generalizaçáo dos resultados.

Apesar do artigo náo trazer a pergunta principal do estudo de forma clara, os autores concluem o presente trabalho com uma síntese dos principais resultados e correlaçóes encontradas.

\section{REFERÊNCIAS BIBLIOGRÁFICAS}

Os autores utilizaram um bom número de artigos científicos, mas deveriam dar ênfase a publicaçóes mais recentes.

\section{REFERÊNCIAS}

1.Scalzo PL, Souza ES, Moreira AGO, Vieira AF. Qualidade de vida em pacientes com acidente vascular encefálico: Centro Clínica PUC-Minas Betim. Rev Neurocienc 2010;18:139-44.

1.2.Laurent R. A mensuração da qualidade de vida. Rev Assoc Med Bras 2003;49:349-66.

2.3.Lima RCM, Teixeira-Salmela LF, Magalhães LC, Gomes-Neto M. Propriedades psicométricas da versáo brasileira da escala de qualidade de vida específica para acidente vascular encefálico: aplicação do modelo Rasch. Rev Bras Fisioter 2008;12:149-56.

3.4.Teixeira-Salmela LF, Magalhães FC, Souza AC, Lima MC, Lima RCM, Goulart F. Adaptação do Perfil de Saúde de Nottingham: um instrumento simples de avaliação da qualidade de vida. Cad Saúde Pública 2004;20:905-14. 